\title{
Free-Riding and Luxury Brands on the Internet
}

\author{
Olivier P. Bomsel ${ }^{1}$ \\ ${ }^{1}$ ParisTech Chair of media and brand economics. Cerna, MINES ParisTech, France \\ Correspondence: Olivier Bomsel, MINES ParisTech, 60 Boulevard Saint Michel, 75006 Paris, France. Tel: \\ 33-1-40-51-90-36. E-mail: bomsel@mines-paristech.fr
}

Received: December 13, 2013

Accepted: January 7, 2014

Online Published: February 24, 2014

doi:10.5539/ibr.v7n3p60

URL: http://dx.doi.org/10.5539/ibr.v7n3p60

\begin{abstract}
Luxury is a complex industrial activity whose products combine strong vertical differentiation and a meaning value for the consumer. Luxury offers experiences, the economy of which is based on signalling. This gives rise to intense intangible investment internalized by trademark law and vertical restraints in distribution. However, the extent of the added value and the power of externalities associated with communication generate many sources of free-riding.

Using the tools of industrial economics, this article analyses how the digitization of information and transactions creates new forms of free-riding in relation to luxury brands. Identifying vertical disintegration as a major source of free-riding, it calls for improved internalization of the enforcement of trademark law by all players in the digital value chain.
\end{abstract}

Keywords: trademarks, internet, luxury, free-riding

\section{Introduction}

\subsection{The Problem}

Subject: See rich without paying the price

A man is often judged by the timepiece he wears-which is yours?

http://mockurl.com/?ef5b66

This is the content of an e-mail that arrived in my inbox and the link referred to a site hosted in Russia containing hundreds of "replica" watches, jewellery, handbags and luxury accessories.

The syntax of the text indicates the use of a machine translator, such as the one offered by Google, which allows the commercial site to send an $\mathrm{html}$ link to recipients worldwide with an intelligible slogan in the local language. The semantic virtue of this pseudo-translation is that it conveys, better than a polished advertising communication, the economic intention of counterfeiting. The consumer is offered the possibility of benefitting from the social signification of luxury without paying the price, by means of a watch - a timepiece - because this is often the way in which men are judged.

E-commerce allows a commercial offer to be sent by means of an $h t m l$ link to all inhabitants of the globe, while the logistical chain linking the merchant's website to the network of counterfeiters and the pool of transporters that will ship the product to the addressee remains largely opaque. The questions that arise are what then are the economic and institutional details of the case, why does e-commerce make brand counterfeiting easier, and what should be done to better internalize trademark enforcement.

\subsection{Enforcing Intellectual Property on the Internet}

Intellectual property differs from material property by the fact that information is not rival, meaning that the property infringer does not deprive the owner neither the society of a specific good, but free-rides on the investment of all the players from the property value chain. The dematerialization of the vertical chain in copyright and trademark distribution has given ground to many free-riding incentives making these institutions more difficult to enforce. Such incentives have been all the more powerful since Internet intermediaries have benefited from a legal derogatory status, sheltering them from the responsibility of damages caused to third parties, and the value to be derived from free-riding was consequent. However, as noticed by Demsetz: "Some resources and activities offer more serious free-rider behavior than do others. Efficiency calls for controls or 
institutional changes that limit the degree of free riding if these changes are less costly to implement than is the resource misallocation costs created by free-rider behavior." (Note 1) While the enforcement of copyright has generated many law cases and a wide economic literature (Note 2), the analysis of the free riding of trademarks remains less explored.

Using the tools of industrial economics, this article analyses how the digitization of information and transactions creates new forms of free-riding in relation to luxury brands. Then, it considers what economic and institutional means should be used to contain them. The choice of the luxury industry is justified by the importance of the semantic and economic function of its brands and the extent of free riding which they engender.

The article starts by outlining the economic characteristics of the luxury industry and the function of its signalling investment. It then shows, from an economic perspective, how trademark law allows this investment to be internalized. Then, it analyses the economic causes and effects of free riding the luxury brands. The next section enlists the new free riding occurrences resulting from digitalization. Finally, it examines the conditions for improved internalization of the application of trademark law by all players in the digital sector.

\section{Economic Characteristics of Luxury}

\subsection{The Luxury Industry}

The economic characteristics of luxury are that, although not formally required, it entails an arbitrary choice on the part of the consumer. This arbitrariness has an individual and a social dimension.

Individual arbitrariness is a hedonistic preference for the qualitative characteristics of the product. The social choice is the assumption by the consumer of the signification of his or hers luxury in the eyes of the community. This signification is often related to a social status. However, status is neither constant nor automatic (Note 3): it depends on the context of consumption - who is consuming, where, how, with what other products, etc. In this function of status or social meaning, luxury goods also carry a media component: they are a means of communication between the individual and society.

The luxury industry is therefore based on a double logic: i) to develop goods or services whose hedonistic value is based on vertical differentiation (Note 4), i.e. an undeniable qualitative and aesthetic performance; and ii) to build social signification around this differentiation, a means of communication between the consumer and society.

These combined dimensions contribute to the industrial organization of the sector. The existence of only one dimension is not enough to create luxury: a high quality premium product or a fashion accessory with strong connotations is not a priori a luxury item (Note 5). The characteristic of luxury therefore focuses on the ability of producers to design and distribute goods or services with high vertical differentiation but which also convey meaning.

\subsection{The Luxury Experience}

The products of the luxury industry are experience goods, and this experience is both individual and social. The qualitative performance of products - materials, resistance, precision, strength, and aging - as well as a number of aesthetic properties - smell, taste and charm - are often not perceived until the product is consumed. The vertical differentiation that characterizes luxury should therefore be efficiently signalled.

In addition, the communication value from a social experience of luxury can only be assessed after it. The social signification of luxury is even more noticeable if it is identified with or linked to experiences, codes or values that are recognized by society. This meaning is obtained from contextual connotations and connections that provide a selection of references: the world of perfume is at times represented by a glamorous actress, at others by the freedom of a horse evoking the codes of the publishing brand (Hermes), etc.

The myth of experience, its sedimentation over time that is sometimes referred to as culture, underpins the social signification of the product and is part of the experience itself. In our seminal example, it is because the watch is a "timepiece" or a testimony to centuries of watchmaking tradition; it is because the art of its design is based on a combination of shapes, materials and mechanical complications that it can demand a high willingness-to-pay for the adoption and communication of such values.

In economic terms, the social dimension of consumption induces non-linear variations in demand according to price (Note 6): influence of fashion, snobbery or ostentation. A bandwagon or network effect is reflected by a utility growing with the number of consumers. Snobbery creates the opposite effect. With regard to ostentation or the Veblen effect, the high price is the utility vector: it is the "see rich" (Note 7) contained in the email on watches. The originality of luxury is that these three effects can be combined in the consumption of a product. 
An older model that has become rare can generate snobbery after it has been fashionable. A haute couture model - snobbery or the Veblen effect - can establish ready-to-wear codes which generate bandwagon effects. However, these economic effects are not natural. They are generated with the product design and communication of the publishing brand in mind. And they are validated by the experience of consumption.

\subsection{The Signalling Investment}

The experience of luxury induces strong adverse selection: the consumer must be informed of the nature and the individual and social utility of the experience offered. The information must address both the extent of vertical differentiation - the quality that justifies, even goes beyond that required of luxury — and the social signification of this differentiation.

Thus, the existence, nature, guarantee, context, accessibility and the individual and social utility of the luxury experience require signalling. This signalling focuses not only on quality but also on the meaning of luxury -its real and imaginary representation, its codes and its aesthetic values - conveyed by the good or service.

Communication with regard to luxury initiates and maintains the flow of messages on the nature, novelty and the individual and social utility of the experience offered. As a result, investment in communication is a strategic factor in this industry. It is primarily intended to highlight and imply the experience proposed to the consumer - and also to allow the consumer who has chosen the luxury item, to communicate with society.

The trends relating to the investment in signalling of perfumes in France between 1985 and 2010 are indicative of this phenomenon (Note 8). During this period, 598 new perfumes were launched. Their names are inherently metaphorical — a complex perfume cannot be described by a straightforward name — and must be identifiable by the customer or the person for whom the purchase is intended, designating a specific experience. The publisher's name - the brand of perfume - guarantees and endorses each new experience on the market. The average number of launches a year increased from 10 in the 1980 s to 40 from 2005 onwards.

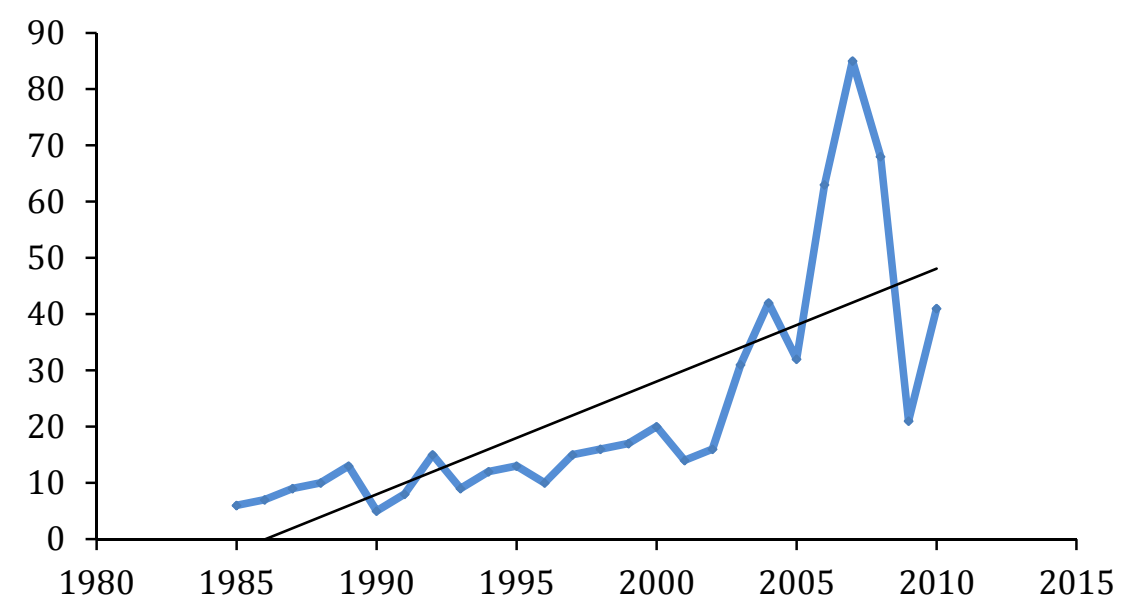

Figure 1. New perfume launches (yearly) between 1985 and 2010 in France

However, the average advertising cost of launching a perfume seems proportional to the number of perfumes simultaneously brought to market (Figure 2): between 1 and 2 million euro from 1995 to 2005, and up to 7 million euro for 40 launches per year. 


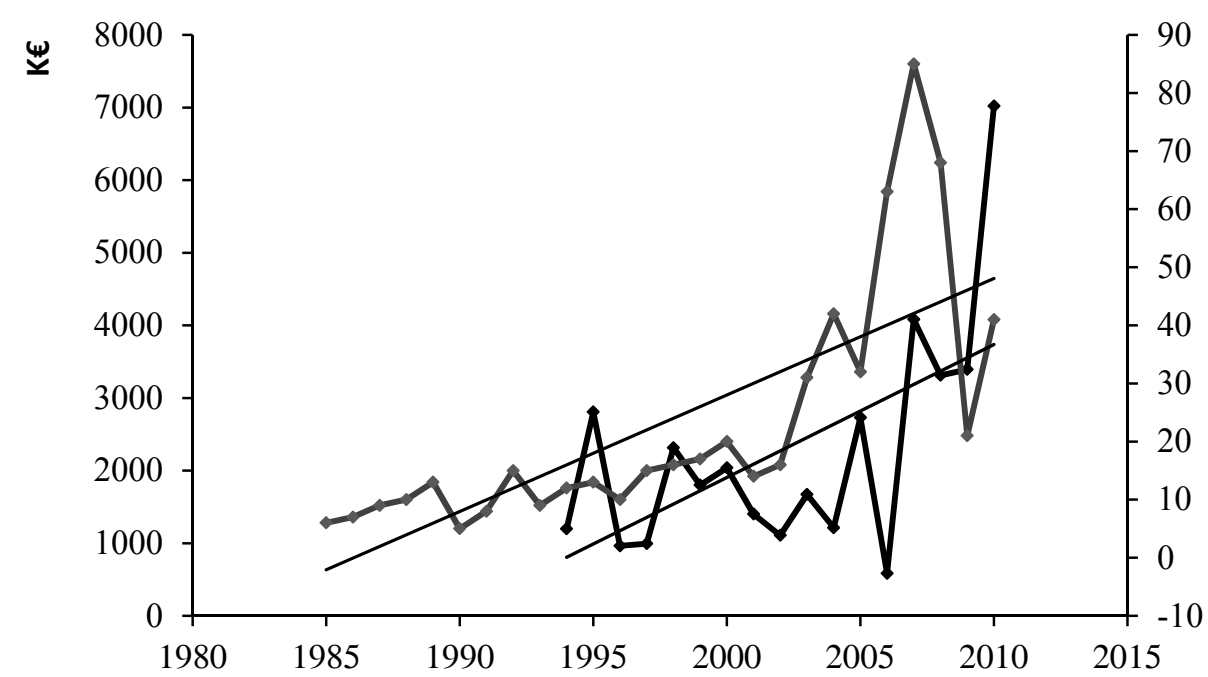

Figure 2. 1994-2010: new perfume yearly launches in France (gray) and advertising expenditures (black) in average at nine months (Note 9).

Source: Kantar Media.

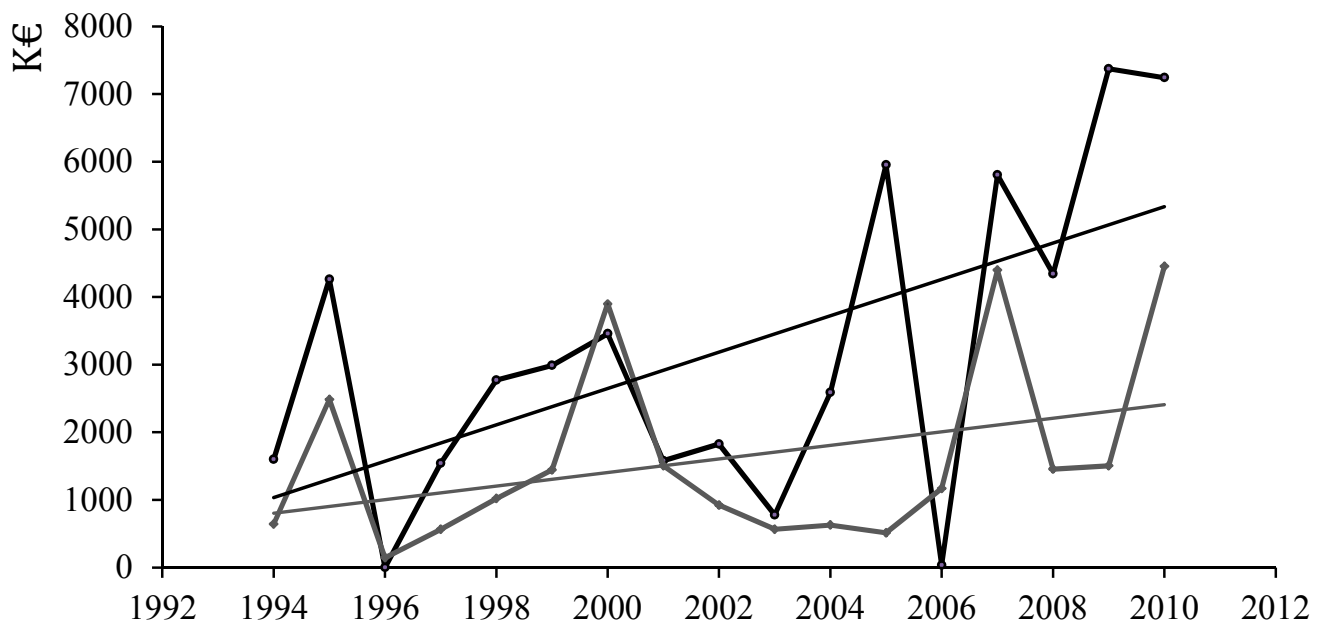

Figure 3. Comparison of average launch cost of a perfume at 9 months between small (gray) and large (black) publishers (Note 10).

Source: KantarMedia.

In addition to the increase in the number of registered publishers, this phenomenon is accompanied by a concentration of major perfume producers in the luxury industry. Large producers are distinguished from smaller producers by the number of launches and the amount spent on advertising per product (Figure 3 ).

Not just limited to the perfume industry, investment in advertising is a critical factor for competition between producers of experience goods, even between luxury goods manufacturers, which offset communication costs and business risks by expanding their reference catalogues. The publishing brands provide economies of scale and scope, which favour the creation and marketing of new references. Thus, the effectiveness of the internalization of investment by these brands influences the industrial organization and competitiveness of the luxury sector. This is also true for all industrial designers of experience goods.

\subsection{The Economic Function of Luxury Brands}

A brand is first and foremost a semantic tool that signals quality. The initial role of a brand is to guarantee product quality. Associated with the company that produces the brand, it crystallizes the reputation effect, providing a guarantee of quality to the consumer. This is critical when adverse selection is important, as is the 
case of experience goods.

The brand is also a sign, an indicator of the consumer's choice, used by him to communicate with society. This re-use mechanism affects all products the consumption of which leads to social signification. It is essential for luxury brands that reflect a commitment when chosen by the consumer. Hence nurturing their signification by dense communication and increasing their evocative power is a strategic investment (Note 11).

The more intense (Note 12) the signification, the more the luxury brand is appreciated. A highly valued brand encourages the creation and vertical differentiation by the producer and the use thereof by the consumer to indicate his choice (Note 13).

By giving the user the exclusive economic use of a name or phrase, trademark law internalizes - the signalling, i.e., the economy of investment in communication (Note 14). In doing so, it also internalizes the investment with regard to creation and quality, which cannot be valued without communication. Trademark law is as essential for the luxury industry as patents are to the pharmaceutical industry or land entitlement for construction. Its definition and effective implementation conditions the profitability of all investments made prior to the consumer experience.

\section{Free-Riding and Trademark Law (Note 15)}

\subsection{External Effects of the Use of Brands}

Like all communication tools, brands generate strong external effects, i.e., an impact affecting other agents than those directly involved in transactions relating to the brand itself. A significant portion of this impact is due to the connotative function of brands. The impact of luxury brands is particularly strong.

A Christian Dior accessory is guaranteed and connoted by the brand to which it refers. Connotation adds to the sense of experience and its prescription. It is an essential element of signalling. This connotation extends to the entire context surrounding the object. Thus, in addition to its intrinsic properties, a luxury accessory also serves to enhance the context of the person who displays it. It values the combination of complementary goods that give luxury the signification intended by the consumer.

To take just one example, the collaboration of Karl Lagerfeld, Chanel's artistic director, with the clothing brand $H \& M$ has given the latter a connotation of luxury, which is appreciated by its consumers. This positive effect for $H \& M$ was the subject of a contract (Note 16). However, conversely, this collaboration also encourages $H \& M$ consumers to wear Chanel accessories without risking ridicule or incongruity. This second effect, mediated by the name of Karl Lagerfeld, can be mutually beneficial to both companies.

This type of economic impact, known as crossed externalities, is a constant of the media and brand economy. These externalities are often internalized by connotation agreements, known as co-branding or endorsement contracts. Many of them also relate to distribution, which contributes to the contextualization of experiences. To dispose a Dior product in front of a Chanel one does not have the same meaning as disposing it front of an own brand detergent or fabric softener. Hence the existence of exclusive or selective distribution agreements binding various types of vertical restraints.

Mastering these crossed externalities is part of the expertise of the luxury industry when manufacturers control the economic use of their brands. Nevertheless, and this brings us to the crux of this article, more and more situations occur which bypass this control. Therefore, externalities give way to free-riding, i.e. to situations where the economic value of brands and the investments that contribute to it benefit third parties to the detriment of the actual rights holders.

\subsection{Free-Riding Luxury Brands}

In economics, the term free-riding refers to the harnessing and use of external effects by third parties that did not contribute to them. The originality of luxury is that it lends itself to free-riding in relation to its investment in quality, as well as its signals. The replica watches on the Russian website do not claim to have the same quality as the original watches; instead they offer the wearer the social signification of these watches. However, this market would not exist without the investment in quality and signalling of the original manufacturers.

A remarkable point is that the websites selling replicas just like our example maximise the value of crossed externalities between luxury brands by presenting, in the same space, the largest possible choice of counterfeit brands. They thus maximize the effect of free-riding, i.e. they harness the value of all of the brands replicated.

Free-riding primarily concerns the production of counterfeit goods in violation of trademark law. These offences are even more difficult to control as they can be committed anywhere in the world and can avail of digital distribution networks. Furthermore, the distribution of counterfeited or free-rode brands can benefit from legal 
loopholes. Such loopholes, as we shall see, are only sometimes identified and, more rarely, overcome. With regard to vertical restraints to limit free-riding in distribution, they are not related to trademark law but to exceptions to competition law granted according to the "rule of reason." (Note 17) These exceptions must be reformulated each time a new distribution method appears.

\subsection{Economic Impact of Free-Riding}

While it is recognized that the counterfeiting of medicines or car parts is harmful to consumers, the economic impact of the parasitism of luxury is the subject of controversy. This is mainly due to the fact that, by definition, luxury is not a necessity therefore its counterfeiting holds no obvious danger. However, the main point is that the lack of quality may suit some consumers as they will nonetheless gain access to the signification of luxury. Thus, the consumer may be interested in fakes (counterfeited brands). This point is crucial because it creates specific incentives that distinguish the parasitism of luxury from other forms of free-riding where the beneficiaries are the sales intermediaries.

Some argue that counterfeiting targets an alternative clientele to that of authentic goods and that by circulating genuine luxury codes, it indirectly contributes to increasing its market (Note 18). In other words, there is a positive externality to the circulation of counterfeit goods.

This may be so. It is possible to imagine in the communities of consumers of fake goods, a snobbery effect that may redirect some of the consumers towards the genuine article. However, this externality is beyond the control of any trademark holders and may as well be reversed. For the loyal consumer, the choice of luxury loses its clarity: the assumption of a high quality choice is no longer meaningful; worse, it becomes a source of misunderstanding. Free-riding then removes the control of the product from the producer and it becomes impossible to master the promotion of quality through signalling.

Finally, the negative externalities of free-riding are more numerous and stronger than the positive ones. Firstly, free-riding leads to a loss of clarity of signals and incentives to invest in quality and communication. It then results in a reduction in investment, which is useful for consumers and society, or in an increase in investment for loyal consumers. Secondly, by creating parallel distribution channels, free-riding penalizes authorised distribution networks and increases luxury marketing costs. Thirdly, where free-riding contravenes or facilitates the circumvention of trademark law, it weakens the institution and undermines its credibility. And finally, it encourages the development of a black economy that is conducive to fraud and money laundering.

\section{The Internet: New Ways of Communication, Distribution and Free Riding}

\subsection{What Changes Has the Internet Made?}

In the physical or face-to-face universe, brand communication flows from the producer to the consumer via the media selected by the company while goods are presented in authorized retail outlets. Of course, the editorial use of brand names is free and the media can relay information relating to the brands without maintaining any explicit contractual relationship with the trademark holders (Note 19). However, as it concerns the physical world, everything that flows outside the authorised distribution channels may be referred to as free-riding, and, whether counterfeit or side-selling, may be attacked for irregular behaviour.

The Internet introduced a radical new structure ( $h t m l$ links, online transactions, separate logistics etc.) for the communication, sales and delivery of physical products. Communication is multidirectional, it includes private correspondence and publications. The sale takes place in the same space. Physical delivery is a separate outcome.

This new vertical order is a source of innovation in traditional communication and distribution channels: it allows communication through new media, automatic product searches, relationships between consumers, the disintermediation of the distributor and the decoupling of the sales and logistics management of products. However, these innovations are also a source of a new free-riding opportunities encouraged by the economic value of brands. This section will focus on the last point.

\subsection{The Html Link}

From a brand perspective, the essential innovation of the Internet is the html link. This link allows completely new forms of association between signifiers, such as new connotations and associations, however it also generates ambiguous relationships and free-riding.

The html link performs two functions: on one hand, it connects the significant elements based on criteria established by the creator of the link, and on the other, it facilitates the transition from the research phase - market exploration - to the transaction phase. 
The first function is exploited by search engines to correlate signifiers using metrics based on semantic proximity or on the density of links. The second function is used by e-commerce.

By means of the html link, the exclusivity of assigning a brand to a product is no longer restricted to the beneficiary. Connotation - the lexical composition associated with luxury brands - allows completely new associations to be created. This fact, reinforced by PageRank, Google's algorithm that directs web pages according to the density of $\mathrm{html}$ links, is a new fundamental element for the practice of trademark law.

Let's look at an example. The word Dior typed into Google returns a page full of links to official Dior references or to the Sephora sales network, and a link sponsored by the company Dior. However, the search term "cheap Dior" returns a page full of links to counterfeit websites.

The html link allows instantaneous correspondence between the display of a brand or a product and its purchase online. In terms of traditional sales activity, it brings investment in communication closer to actual turnover. However, the $\mathrm{html}$ link also values as all of the free-riding connotations and creates a powerful incentive for free-riding by carrying out ad hoc lexical compositions. In the physical world, asking for "cheap Dior" at a point of sale would be considered an infringement. In the digital world, a lexical composition incorporating a luxury brand can be used to access counterfeited goods. If the Internet user is the one who formulates such a lexical composition, there can be no question of preventing him from doing so.

In addition, there is also the possibility of direct marketing, which, by providing counterfeiters with access to large databases, extends the effectiveness of $\mathrm{html}$ links to active solicitation by e-mail.

Thus, in the physical world, obtaining counterfeited goods for the consumer entails a cost, namely to move to a geographical area where the points of sale exist. This action also facilitates the monitoring and enforcement. The html link allows a radical decoupling of research and sales, minimising the cost of research for the consumer and encouraging free-riding due to the fact that counterfeiting is hard to suppress.

\subsection{Word Markets}

The market for domain names is the first front on which trademark law was challenged. The first arrivals snapped up the words that were most likely to generate traffic and transactions, including, of course, the luxury brands. Regulation (Anticybersquatting Consumer Protection Act, 1999) put some order on things by giving priority to trademark owners to access eponymous domain names. The use of lexical compositions incorporating the names of brands was then used to label counterfeit sites. This approach aimed at presenting counterfeit products as the genuine article, leads the consumer to believe that the merchant site is endorsed by the brand. However, ultimately, the use of this mechanism is often less effective for free-riding than being anonymously referenced on the search engine of a multi-brand website.

The other major issue is the creation of keyword markets by search engines. Keywords are used to display the results of sponsored links to commercial websites. The sale of keywords by third parties deprives the brands of the exclusive use of their own trademark. In fair use, sponsored links lower search costs and facilitate consumer contact with the brands. However, in the absence of rules, the brand names of publishers or products can also be purchased to sell competing or counterfeit products. In this case, the seller of keywords parasites a trademark signal for the benefit of third parties (Note 20). This practice, strongly opposed by the rights holders, was sanctioned (Note 21) by a decision and supported by another (Note 22) on behalf of comparative advertising. On Google, the sponsored links that were returned for the query "cheap Dior" related to legal discounters and the official Dior website. (Note 23)

However, although rights holders can supervise practices relating to sponsored links, they are not familiar with search engine algorithms and cannot prevent the referencing of illegal sites or their appearance on results pages. The responsibility of the search engines which receive advertising revenue for this service has not, to date, been formalised.

Finally on this point and to balance the argument, search engines also prove invaluable to rights holders to identify, monitor and locate counterfeiting networks.

\subsection{Social Networks}

Social networks are the new media that group together a mix of private correspondence and public communication.

Facilitating exchanges between consumers and even creating affinity groupings, social networks facilitate the deployment of fashion and reputation effects (network effects). Some brands (Google, Facebook and non-web brands, such as Michel \& Augustin) have managed to enhance their reputation and image from the 
communication spread by social networks.

Social networks can contribute to the maintenance of values and the affinity for a luxury brand, testing new experiences and marketing new products. Networks socialize experiences, potentially raising the individual and collective value of products and providing their producers with feedback.

However, network effects work in both directions: if the firm makes a communications error (such as inappropriate statements by Jean-Paul Guerlain, John Galliano, or Gucci's conflictive industrial relations in China), it is communicated even more strongly as the brand supporters are all interconnected. A community of organized consumers can become a pressure group.

To return to our main theme, whenever the vertical chain of luxury is opened up to new players-in this case, communities of consumers who share their experiences - new forms of free-riding will occur. In other words, whenever a positive externality appears in luxury communication, its equal opposite is not far away because all of the elements that contribute to the value of luxury also encourage free-riding.

Thus, the forums of fans of a brand are ideal target for counterfeiting activities. Intermediaries can infiltrate the groups and add links to counterfeiting sites. Some customers will follow the links. Others will be bothered by the vicinity of fakes.

The problem here is that social networks-Facebook, YouTube and Google+ —are not aware of the exact identity of their members and are not responsible for their actions. In general, the network operator is ready to intervene if the actions of its members affect its traffic or reputation (Note 24) but not if they cause harm to third parties.

The basic issue is that anonymity is the main feature of media forums and operators play censorship or moderation roles. From this perspective, operators do not consider themselves merely as hosts but as the media responsible for the meaning transmitted. However, this responsibility is limited to their own interests. Therefore, the free-riding of a forum for the sale of counterfeit goods is not considered by the media to be a disutility for their customers and they therefore have no incentive to censor it. Worse still, if they consider that the free-riding behaviour of a member actually generates traffic, they might actually allow such activity to flourish.

This is probably a temporary situation because media regulation aims to require operators to internalize all of the negative externalities that may be generated. The rules governing advertising in newspapers or on television, including the separation of advertising from editorial elements, are far more stringent than those applied to the Internet today. There is no reason why the two systems should not converge further.

\subsection{Online Transactions}

E-commerce is a significant source of savings with regard to distribution (Note 25). It allows the separation of sales and delivery logistics. With regard to luxury, the distribution of which contributes to the overall consumer experience and therefore cannot dispense with physical networks, the management of the complementarity between physical networks and digital networks is strategic (Note 26). Otherwise, online distribution may free-ride on physical distribution. To avoid this phenomenon, European regulations allow luxury producers to require that the online distributor also operate a brick-and-mortar activity (Note 27). This complementarity is a source of competition and helps to raise the overall efficiency of the distribution channel.

However, e-commerce opens up end markets to resellers worldwide, lending itself to free-riding which benefits from economies of scale, disintermediation and legal offshoring, whereas standard distribution channels must maintain physical networks at all costs.

Websites selling counterfeit goods can be hosted in tax havens or in countries with little regard for intellectual property. They use methods of payment that are approved by legal markets. The manufacturing networks that supply them can be fragmented and compartmentalized. Closer to the consumer, individuals can fit into the chain and can act as an intermediary for their friends, providing them with access to counterfeit goods. This practice (drop-shipping) does not turn the intermediary into a counterfeiter or a fence, but a commercial agent (usually anonymous) of the counterfeiter. This accumulation of legal barriers to law enforcement increases the cost and decreases the efficiency of any action taken.

Add to this the role of sales platforms and exchanges between individuals whose operators are well identified. Like social networks, they use mixed media-B2C and $\mathrm{C} 2 \mathrm{C}$ exchanges - and merchant sites. Their interest in respect of trademark law differs depending on whether their model is based on $\mathrm{B} 2 \mathrm{C}$ sales commissions or remuneration through the use of auction systems $(\mathrm{C} 2 \mathrm{C})$ and their ability to control the reliability of such exchanges. For several years now, cooperation strategies between eBay and PriceMinister and the brands have 
significantly diverged. e-Bay, which receives a commission based on the $\mathrm{C} 2 \mathrm{C}$ transactions between its members, has shown little regard for the lawfulness of such transactions (Note 28). PriceMinister, more oriented towards $\mathrm{B} 2 \mathrm{C}$, has been more interested in securing its customers.

Most platform operators wish to hide behind the derogatory status of a host which is legally viewed as a technical service provider discharged from all liability with regard to the activities of their clients. During the deployment phase of digitization, they took advantage of this status to build new markets. Basically, limiting the liability of technical operators accelerated the deployment of the Internet of which the social benefits - the positive externalities - surpassed all of the negative externalities, especially for rights holders of Intellectual Property (Note 29). As this deployment is now complete, it is likely that the negative effects of this status, notably on intellectual property, will lead to a review and the re-definition of the responsibilities of the various actors in the digital channel (Note 30).

\subsection{Physical Delivery}

Like online sales, delivery is a service that sits within the vertical chain. It provides differentiated services: lead time monitoring, package tracking, etc. Free-rider distributors - usually based far away from the target market - cannot guarantee the same transparency or the same quality of service as authorized networks.

As regards imported products, delivery is the critical link in combating fraud. Unlike face-to-face distribution, counterfeit goods purchased on the Internet are delivered by mail to the consumer. Control of the postal delivery of orders, which follows heavy industrial constraints (Note 31), has generated many customs seizures. These seizures are less significant (Note 32) than those supplying the physical retail channels, however they directly affect the consumer who loses the amount of the order and must apply to the seller for a refund. They serve as a warning which increases the risk of the buyer of counterfeit goods and undermines confidence in e-commerce. This creates incentives for online sellers to promote legal distribution and to fight against the sale of counterfeit goods.

\section{Adapt the Economy of Law Enforcement}

\subsection{Extension of Free-Riding}

Luxury is a complex industrial activity whose product combines strong vertical differentiation and signification in the eyes of the consumer. Luxury offers experiences, the economy of which is based on signals. This gives rise to intense intangible investment internalized by trademark law and vertical restraints in distribution. However, the magnitude of the wealth created and the power of externalities associated with communication provide sources of free-riding.

Europe is better off economically with the creation of luxury goods and signals which add value to its cultural heritage and whose experiences are not impeded by the barriers of language. Europe must therefore focus on the protection of investments in this sector.

Digitization, $h \mathrm{tml}$ links, electronic communication and e-commerce upset the vertical chain of the application of trademark law. This introduces new sources of free-riding which complicate and increase the costs of law enforcement, not only for luxury goods but for all sectors involved. This weakens the trademark institution as the greater the cost involved in enforcing a right to property, the more its legitimacy is challenged.

Although it is impossible to measure counterfeiting since it is an underground practice, it is certain that with the increased productivity of online distribution, counterfeit markets and industries are increasing and the free-riding economy is expanding. We can consider that its development follows at least the growth rate of e-commerce.

\subsection{Towards Greater Responsibility}

The traditional mechanisms used to enforce trademark law, i.e. seizures by national customs, the exclusion of counterfeit products from the market, the targeting of counterfeiting industries, not to mention increased consumer responsibility, are not enough to contain new forms of free-riding. The international dimension of e-commerce requires greater systematic cooperation between countries to enforce trademark law. The distribution of counterfeit goods is no longer a local problem. The impunity of one area is enough to create very strong incentives for fraud, relayed by all means of digital access. Therefore, the different countries must, now more than ever, ensure that counterfeiting does not thrive at a national level.

But that's not all. To limit the spread of free-riding, there should be improved internalization of the application of trademark law by all actors throughout the digital chain. In in the physical economy, this form of internalization operates through vertical restraints in distribution, which facilitate the identification and seizure of counterfeit goods. However, in the digital economy, the actors of the html link chain are more diverse and numerous. If the 
actors in this chain are not held accountable for the free-riding of other industries, yet more opportunities and possibilities for complicity will be identified.

To date, regulators have focused on developing digital innovation by limiting the liability of actors vis-à-vis external effects on other industries. However, the spectacular development of the free-riding of intellectual property requires new practices to be implemented. It is difficult to legally require a provider, a search engine or a social network of service to eradicate any form of free-riding from the service it provides. Nevertheless, better cooperation between industry leaders is certainly possible. This requires practices that aim tendentiously to reduce the negative externalities towards intellectual property, or more specifically, to establish a duty of care requirement for intermediaries (Note 33). This requires a concrete definition of free-riding practices and legal threats to force the industry cooperate.

This threat arises with the case-by-case examination of the applicability of tort law to Internet intermediaries, which - as a result of the decision of the Court of Justice of the European Union in July 2011 — redefines the hosting status to avoid any misuse or abuse (Note 34). If the burden of proving the validity of host status is placed on the hosting provider itself, the economics of tort law are used in the development of Internet services: those involved in the digital chain - from access provider to payment manager-are now at risk of being called into question in relation to an offence. Anticipating this risk then guides technical innovation towards reducing free-riding and intellectual property application costs.

Last but not least, holding intermediaries accountable allows legal claimants to avoid having to resort to criminal law, especially if the consumer is involved: it is costly and degrades the perception of the brand. Without suppressing fraudulent purchases, publicity surrounding postal seizures maintains a feeling of insecurity that deters consumers from accepting dubious offers or counterfeited goods. Thus, "looking rich without paying the price," becomes a little more expensive for the consumer through the greater involvement of e-commerce actors, which have no interest in seeing their environment deteriorate. Such an approach, which leads to an awareness among postal operators of the internalization of law enforcement, can only encourage all agents of the digital economy to adopt greater transparency and fairness.

\subsection{Implications for Academic Research}

From an academic standpoint, this approach opens a new field of research in the economics of tort law. While traditional approaches consider tort law as a means to internalize potential damages caused to third parties by anticipating the amount of the penalty resulting from being held responsible (Note 35), the greater uncertainty on the validity of the hosting status suggests an extension of this thinking to intellectual property enforcement. The main difference with usual tort law economic approaches concerns the uncertainty on the level of responsibility that can be attributed to an intermediary. As it is the judge who decides to what extent should the hosting status apply or not, the intermediary is subject to a legal risk that he should try to minimize, whether by restricting the burden of his non hosting services, whether by increasing his vigilance and care about intellectual property. Some academic research modeling the behavior of the agents facing legal uncertainty is currently being published on this matter (Note 36).

\section{References}

Bastien, V., \& Kapferer, J. N. (2008). Luxury Forces. Paris: Eyrolles.

Belleflamme, P., \& Peitz, M. (2010). Industrial Organization: Markets and Strategies. Cambridge University Press. http://dx.doi.org/10.1017/CBO9780511757808

Bernstein, F., Song, J.-S., \& Zheng, X. (2009). Free riding in a multi-channel supply chain. Naval Research Logistics, 56, 745-765.

Bomsel, O., \& Ranaivoson, H. (2009). Decreasing Copyright Enforcement Costs: The Scope of a Graduated Response. Review of Economic Research on Copyright Issues, 6(2), 13-29.

Bourdieu, P. (1979). La Distinction. Paris: Ed Minuit.

Demsetz, H. (2009). Creativity and the Economics of the Copyright Controversy. Review of Economic Research on Copyright Issues, 6(2), 5-12.

Kariithi, N. K. (2011). Is the Devil in the Data? A Literature Review of Piracy Around the World. The Journal of World Intellectual Property, 14, 133-154. http://dx.doi.org/10.1111/j.1747-1796.2010.00412.x

Landes, W. M., \& Posner, R. A. (1987). The Economic Structure of Tort Law. Cambridge (MA): Harvard University Press. 
Landes, W, M., \& Richard, A. P. (2003). The Economic Structure of Intellectual Property Law. Cambridge, Mass: Harvard University Press.

Lefort, M. (2013). Copyright enforcement and quality differentiation on the Internet. Review of Economic Research on Copyright Issues, 10(2).

Leibenstein, H. (1950). Bandwagon, Snob, and Veblen effects in the Theory of Consumers' Demand. Quarterly Journal of Economics, 64(2). http://dx.doi.org/10.2307/1882692

Perrino, M. (2007) Contrefaçon et ostentation. Revue d'économie industrielle, 117.

Rey, P., \& Tirole, J. (1986). The Logic of Vertical Restraints. The American Economic Review, 76(5), 921-939.

Sayed, A., Jerath, K., \& Srinivasan, K. (2011). Competitive Poaching in Sponsored Search Advertising and Strategic Impact on Traditional Advertising. Working Paper, Carnegie Mellon University.

Terré, F. (2011). Etre ou ne pas être responsable. La Semaine juridique, 43-44.

Watt, R. (2000). Copyright and Economic Theory, Friends or Foes? Northampton, Ma, USA: Edward Elgar.

\section{Notes}

Note 1. Demsetz, H. (2009). Creativity and the Economics of the Copyright Controversy. Review of Economic Research on Copyright Issues, 6(2), 5-12.

Note 2. For a recent and extensive literature review, see Kariithi, N. (2011). Is the Devil in the Data? A Literature Review of Piracy Around the World. The Journal of World Intellectual Property, 14(2), 133-154.

Note 3. Contrary to the assumptions of a "class-conscious" sociology which is based on the existence of a rigid social hierarchy. We refer here to Distinction, as described by Pierre Bourdieu, for whom consumption is driven by the desire to imitate the upper classes. Ed Minuit, Paris, 1979.

Note 4. Vertical differentiation, based on "objective" quality criteria, is opposed to horizontal differentiation which reflects variations without any impact on performance: colour, size of clothing, etc.

Note 5. Theory developed by Vincent Bastien and Jean-Noel Kapferer in Luxe oblige, Eyrolles, 2008, pages $53-62$.

Note 6. See Leibenstein, 1950.

Note 7. i.e. how to "look rich."

Note 8. Ongoing research by the ParisTech Chair of Media and Brand Economics on the "Cost of creating brands." Survey of brands established by Publicis. Data supplied by Kantar Media. The three graphs are taken from this research.

Note 9. Deflated on 1994 prices in K€.

Note 10. Small (resp. large) means less (resp. more) than 10 launches for the period 1985-2010.

Note 11. Economists call this form of communication "complementary advertising" because it complements the intrinsic utility of the product. Belleflamme and Peitz, 2010. Chapter 6, page 136.

Note 12. e.g. the more it suggests a high concentration—time-based, digital and aesthetic —of experiences.

Note 13. Landes and Posner (2003).

Note 14. Internalization is the allocation of the profit or cost of an action to agents without which it would remain outside the scope of the economy.

Note 15. The terms parasitism or free riding mean opportunistic behaviour that is possibly lawful but socially harmful; the term fraud refers to a specific offence which is punishable by law.

Note 16. "Lagerfeld for H\&M", 2004. According to Lagerfeld, this collaboration ended because H\&M did not sufficiently publicise and promote the products designed by the creator. H\&M therefore parasited Lagerfeld. The “snobbery" of H\&M annoys Karl Lagerfeld, L'Expansion.com — published on 17/11/2004.

Note 17. See P. Rey and J. Tirole (1986).

Note 18. (Muriel \& Perrino, 2007). This thesis also flows in the economic debate on copyright. (Richard Watt, 2000).

Note 19. This does not prevent the implicit management of crossed externalities—in addition to editorial and 
advertising campaigns - by the media and luxury producers.

Note 20. The question of free-riding by Google in the capture of advertising investment has generated an abundance of literature. (Sayed, Jerath, \& Srinivasan, 2011).

Note 21. A landmark ruling by the European Court of Justice (ECJ) upheld Louis Vuitton's right to prevent the use of its brand as a keyword. However Google's responsibility means that the use of this keyword is not systematically undertaken. ECJ, 23 March 2010, case C-326, 237 and 238/08.

Note 22. The decision of the ECJ of 22 September 2011 (C-323/09, Interflora vs. Marks \& Spencer) states that "the owner of a famous brand name is entitled to prevent, in particular, advertising displayed by competitors using the key words for this brand and offering an (...) alternative to products or services of the owner thereof."

Note 23. Other brands (Moncler, for example) seem less effectively protected.

Note 24. YouTube had to intervene actively in 2010 after members, furious at the withdrawal of copyrighted music videos, posted hidden pornographic videos online.

Note 25. Through a need for brevity, we are dealing here with e-commerce platforms most of which use standard payment systems that add an additional intermediary to the $h t m l$ chain.

Note 26. If it offers better prices, online distribution may interfere with physical distribution. See Bernstein, Song, Zheng, 2005.

Note 27. Exemption by category applicable to vertical relations 330/2010.

Note 28. After four years of proceedings, the Paris Court in February 2010 fined e-Bay 200,000 euro in damages and 30,000 euro in court costs for damage to the brand's reputation, its corporate name, the logo and the domain name of Louis Vuitton.

Note 29. See Bomsel and Ranaivoson, 2009.

Note 30. The decision of 12 July 2011 the European Court of Justice (ECJ) formally recognizes the responsibility of eBay in the sale of counterfeit L'Oreal products, thus restricting the scope of its special status of host.

Note 31. Approximately 6 million objects pass daily through the postal hub in Roissy in a very short space of time. 2 million items relate to international flows. It is impossible to interrupt this flow. 20 million customs declarations, generally vague, are received annually for imported express freight packages. See the working paper "Means of application of trademark law," ParisTech Chair of Media and Brand Economics, 2010.

Note 32. 5000 items per month at the postal hub in Roissy where 30 customs officers work out of the 800 present in the entire airport area. Between 2007 and 2009, the number of items seized in express freight increased from 1\% to $10 \%$ of total seizures. $70 \%$ of the items seized came from Asia and $65 \%$ of China. Ibid.

Note 33. It is the duty to act positively to protect others from damage when the seriousness of the harm on the one side and the ease of avoiding the damage on the other side point towards such a duty. Art. 4: 103, Common Principles of European Tort Law.

Note 34. The novelty of this judgment on the dispute between L'Oréal and eBay is brilliantly narrated by F. Terré in Etre ou ne pas être... responsable [To be or not to be... responsible]. With regard to Internet service providers: JCPG2011, 1175. The demonstration of abuse of the status of hosting provider is also at the core of the indictment of Megaupload ( $\operatorname{Jan} 2012$ ).

Note 35. See Landes, W. M. and Posner, 1987.

Note 36. Lefort, Marine, 2013.

\section{Copyrights}

Copyright for this article is retained by the author(s), with first publication rights granted to the journal.

This is an open-access article distributed under the terms and conditions of the Creative Commons Attribution license (http://creativecommons.org/licenses/by/3.0/). 